\title{
Video conferencing in the e-learning context: explaining learning outcome with the technology acceptance model
}

\author{
Daniel R. Bailey ${ }^{1} \cdot$ Norah Almusharraf $^{2} \cdot$ Asma Almusharraf $^{3}$ iD
}

Received: 2 November 2021 / Accepted: 9 February 2022 / Published online: 21 February 2022

(c) The Author(s), under exclusive licence to Springer Science+Business Media, LLC, part of Springer Nature 2022

\begin{abstract}
This study uses the technology acceptance model (TAM) to help explain how the use of technology influences learning outcomes emanating from engagement with the Zoom video conference platform. To this end, structural equation modeling was used to analyze the relationships among the TAM variables in reference to Zoom taught during the Covid-19 pandemic. Following a cross-sectional research design, data were collected using Davis's TAM (1989) scales including perceived ease of use (PEoU), perceived usefulness (PU), behavioral intentions, and attitude from 321 South Korean university students attending their $10^{\text {th }}$ week of English as a foreign language (EFL) conversational English classes. Results revealed that seven of the ten proposed hypotheses were confirmed, with path coefficients having small to large effect sizes. Most notably, PEoU with Zoom strongly affected PU and actual use. In addition, PU with Zoom predicted intentions to use Zoom in the future; however, it failed to influence perceived learning outcomes. While PU predicted future use, it did not influence actual use regarding how well students reported their current performance in their video conference course. PEoU with video conference tools was an influential antecedent to usefulness, attitude, and perceived learning outcome. Lastly, two notable instances of mediation through PU occurred. In consideration of findings, students and instructors should be well trained on the use and functionality of video conference software before its implementation in video conference classrooms.
\end{abstract}

Keywords Technology acceptance model $\cdot$ Video conference $\cdot$ Zoom $\cdot$ Computerassisted language learning $\cdot$ Covid-19

Asma Almusharraf

amusharraf@imamu.edu.sa

Extended author information available on the last page of the article 


\section{Introduction}

Methods addressing challenges faced during the e-learning adoption in the context of higher education were reported during the emergency remote teaching in the wake of Covid-19 campus closures (Almaiah et al., 2020; Ho et al., 2020; Vladova et al., 2021). To overcome social distancing issues, several studies addressed the use of educational e-learning platforms with video conferencing tools that dominated teaching and learning, including Zoom, Microsoft Teams, Moodle, and Google Classroom (Alfadda \& Mahdi, 2021; Bui et al., 2020; Mailizar et al., 2021; Virtič et al., 2021). The effectiveness of these video conference platforms was evident during the pandemic spread and offered an appropriate solution to the difficulties with emergency online teaching (Pal \& Vanijja, 2020).

Several studies during the Covid-19 pandemic incorporated the technology acceptance model (TAM) as a framework to understand how technology was utilized during the online classes. The TAM, initiated by Davis (1989), is one of the most well-established conceptual models in interpreting and predicting the implementation behavior of Information Technology (IT) (Chang et al., 2017) and helped guide the implementation of e-learning tools during the Covid-19 pandemic. Amid Covid-19 emergency remote online classes, studies looked at e-learning systems (Almaiah et al., 2020; Ho et al., 2020) and online learning tools in general (Mishra et al., 2020). However, there is a need for TAM studies that specifically reference video conference platforms during the Covid-19 pandemic (Alfadda \& Mahdi, 2021).

The video conference platform Zoom was the referenced technology of interest in this study. This is a widely used video conference platform that allows for multiple ongoing sub-conferences referred to as breakout rooms (BOR). In a BOR, instructors can separate students into partners and groups to independently practice conversational English. In conventional offline settings, conversational English classes are collaborative in nature and help develop social ties among classmates (Farr \& Murray, 2016). In English as a foreign language (EFL) classes that focus on conversation skills, having only one speaker at a time becomes problematic because it decreases the amount of student-speaking time. To compensate while teaching in video conference settings, the instructor can create breakout rooms that allow students to work together independently from the main class and instructor. In these sub-conference rooms, the instructor can have students participate in partner and group activities, and the students are responsible for using English while in their groups outside the instructor's supervision. In addition to the BOR function, Zoom allows for several multimodal communication opportunities in online settings, including the use of group and one-to-one chat options, attention indicators (e.g., smiling faces and raising hands, and screen-share options. Other Zoom features include audio-only (i.e., no camera), whiteboard, annotation tools, file sharing, and meeting recordings. 


\subsection{Proposed model}

The proposed model in Fig. 1 illustrates the variables of interest from the TAM framework and how they are expected to help explain the reported levels of actual use as it pertains to perceived learning in video conference courses.

This study incorporated the TAM to help explain how Zoom video conference features contribute to learning outcomes in conversational English courses taught during the Covid-19 pandemic. The TAM framework helps explain behavioral intentions and the actual use of technology (Davis, 1986), and studies suggest PEoU influences PU, while both TAM variables influence attitude and behavioral intentions to use the referenced technology in the future (Almaiah et al., 2020). Myriad studies have used the TAM as a framework to investigate different learning technologies like e-learning systems (Coman et al., 2020; Park, 2009), including mobile learning (Park et al., 2012), formal Learning Management System (LMS) software (Alharbi \& Drew, 2014; Revythi \& Tselios, 2019) and e-portfolio tools (Abdullah \& Ward, 2016). The reason for the wide use of the TAM is its flexibility with a variety of technology devices and platforms, and according to Saadé et al.'s (2007) comparative study, the TAM is a solid theoretical model whose validity can extend to the multimedia and the e-learning context.

\subsection{Proposed hypotheses}

The modified TAM used in the current study referred to attitude pertaining to conversational English activities assigned during the video conference classes (e.g., partner and small group EFL speaking activities). Previous studies utilized the TAM to examine factors related but not limited to experience, perceived usefulness, technology anxiety, and technology self-efficacy (Abdullah \& Ward, 2016; Chang et al., 2017). TAM findings during Covid-19 indicate PEoU and PU with educational technology directly influenced students' attitudes and behavioral intentions (Almaiah et al., 2020; Ho et al., 2020; Mishra et al., 2020). In line with the established TAM framework, the following hypotheses are posited to help

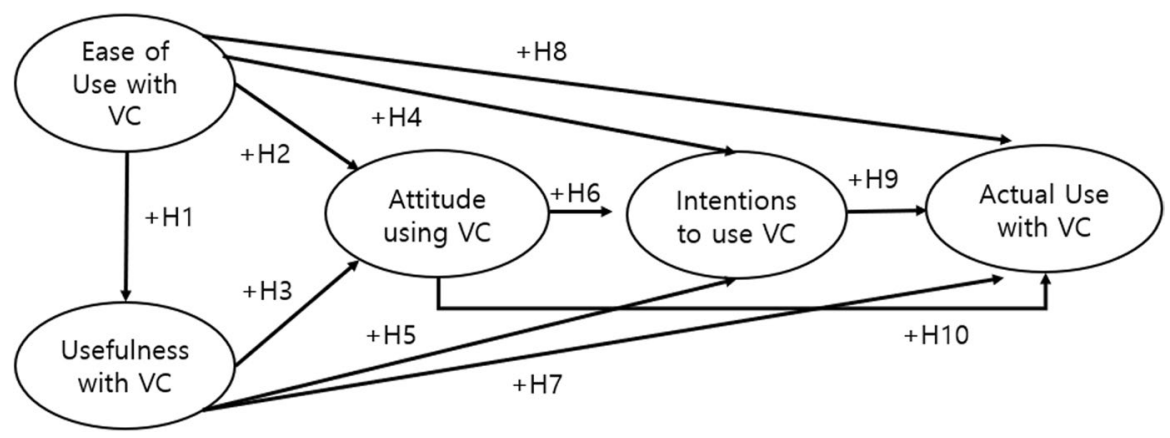

Fig. 1 Proposed Model (Davis, 1986) 
explain the PU and attitudes towards the use of the Zoom video conference platform during the Covid-19 pandemic:

H1: Perceived ease of use positively affects perceived usefulness with video conference tools.

H2: Perceived ease of use positively affects attitudes towards using video conference tools.

H3: Perceived usefulness positively affects attitudes towards using video conference tools.

When participating in video conference courses through Zoom, ease of use, usefulness, and attitude towards the learning environment are proposed here to influence behavioral intention and actual use. The TAM suggests several external variables that influence users' decisions about when and how to use a specific technology. These variables are determinants of PU and PEoU, which involve individual differences, system characteristics, social influence, and facilitating conditions (Venkatesh \& Bala, 2008). There is a current need to understand how the TAM framework can help explain behavioral intentions and actual use when referencing video conferencing features in fully online synchronous classes taught using the video conference platform Zoom. Understanding these factors can help identify the influence attitude has on the relationship between the use of video conference tools and expected learning outcomes. To explain 'users' technology adoption behaviors, it is essential to understand the external variables of PU and PEoU (Al-Gahtani, 2016). To this end, the following hypotheses were posited:

H4: Perceived ease of use positively affects behavioral intentions with video conference tools.

H5: Perceived usefulness positively affects behavioral intentions with video conference tools.

H6: Attitude positively affects behavioral intentions with video conference tools.

Modifications are warranted with the TAM framework in the e-learning context when reported perceptions and acceptance of the referenced technology is connected to learning outcomes pertaining to the actual use (Alfadda \& Mahdi, 2021). In communication courses like conversational English, a required university course in South Korea, participation on the video conference platform through active conversations equates to higher learning expectations because participation is a crucial grade component (Crosthwaite et al., 1986). Following Alfadda \& Mahdi's (2021) use of the TAM with EFL student, actual use was defined as perceived learning that occurred using the video conference platform, Zoom. Using the TAM to explain actual use as it pertains to expected learning outcome, the following hypotheses were put forward:

H7: Perceived usefulness positively affects reported learning outcomes with video conference tools. 
H8: Perceived ease of use positively affects reported learning outcomes with video conference tools.

H9: Behavioral intention positively affects reported learning outcomes with video conference tools.

H10: Attitude positively affects reported learning outcomes with video conference tools.

\section{Literature review}

\subsection{Technology acceptance model}

The TAM is an information system theory that forms how users accept and use technology and is based on Fishbein \& Ajzen's (1975) theory of reasoned action, which posits that pre-existing attitudes and behavioral intentions drive individual behavior. The TAM proposes that a user's attitude toward a new technology determines whether the user will use or reject the technology. Such an attitude is influenced by two significant beliefs: PU and PEoU, both directly affecting learners' intention to use technology (Al-Gahtani, 2016; Lee et al., 2014; Tarhini et al., 2014).

Similarly, Al-Gahtani (2016) confirmed that most of the hypotheses of the TAM are supported, suggesting that better organizational e-learning management can lead to greater acceptance and effective implementation. The TAM is not without criticism. Chuttur (2009) found fault with the TAM for its limited explanatory and predictive power, leading to a lack of practical value. To offset Chuttur (2009) criticism, researchers can substitute learning outcome beliefs for user log data to extend the TAM application and practicality into the e-learning context (Alfadda \& Mahdi, 2021).

Variables within the technology acceptance model include perceived ease of use, perceived usefulness, attitude, behavioral intentions (i.e., future use), and actual use. The TAM can be used to explain further variance in technology use with the inclusion of additional exogenous variables such as subjective norms, experience, and joy (Chang et al., 2017). Typically with the TAM, the most critical constructs are PU and PEoU. PU refers to the extent to which one believes that using specific technology will develop their performance, whereas PEoU partly refers to the mental effort and ease of learning exerted when using technology (Davis, 1989). In the educational contexts, TAM has been explored to verify how learners' PU and PEoU affect their acceptance of e-learning technology (Park, 2009) and their behavioral intention to use that technology in future circumstances (Al-Gahtani, 2016; Almaiah et al., 2020; Lee et al., 2014; Tarhini et al., 2014). According to Pajo \& Wallace (2001), successful technology integration in the learning context depends on available technologies and how they are embraced and used. Similarly, Pituch \& Lee (2006) noticed that PU and PEoU determine learners' acceptance and overall e-learning performance.

Attitude is defined as the degree to which a user is interested in using the system. According to Davis (1989), attitude is the determinant of behavioral intention, leading to actual system usage. Saadé et al.'s (2007) TAM study on 362 students in 
the e-learning context indicated that PU significantly affects university learners' attitudes toward multimedia learning environments. Their study revealed that learners' attitudes affect their behavioral intention to use technology. If instructors and learners find e-learning valuable and easy to use, they will develop a positive attitude towards it.

Several studies have shown attitude as an essential factor in acceptance behavior (Alharbi \& Drew, 2014). Cheung \& Vogel (2013) investigated students' attitudes and revealed that PEoU and PU influenced students' attitudes toward technology. PEoU was also found to predict PU and to be a stronger predictor of attitude than PU.

\subsection{Video conferencing tools and TAM}

During the Covid-19 pandemic, video conferencing tools such as Zoom, Google Meet, and Microsoft Teams became popular teaching platforms to replicate faceto-face classes (Al-Samarraie, 2019). Video conferencing tools are defined as realtime audio and video means of communication between individuals from geographically different places (Mader \& Ming, 2015). However, the effectiveness of such platforms depends on both PU and PEoU (Park, 2009). Those e-learning platforms should provide learners with tools and features needed to support learning that is useful and easy to use. Through a proposed usability framework for e-learning tools, Zaharias (2009) found that students could not achieve complex learning tasks using e-learning systems without help. The poor accessibility of the platform might cause learners' dissatisfaction and reduce their learning (Zaharias, 2009). To best provide help, Granic \& Marangunic (2019) found that there is a demand to address learners' acceptance, attitude, purpose, and use of video conferencing tools, among other technological learning tools, early in the implementation process.

Pal \& Vanijja (2020) have implemented a survey among university students that measures the usability of Microsoft Teams as a reference platform based on the TAM. They concluded that a higher perception of usability leads to the adoption of the online platform. Similarly, Taat \& Francis (2020) conducted a study to assess students' acceptance level of e-learning and identified factors that influence it. Their study showed that students' acceptance of e-learning is influenced by the benefits and usefulness of the online platform that could, in turn, enhance the effectiveness of learning online. Moreover, in a study by Alfadda \& Mahdi (2021), the PEoU and PU are considered to affect the acceptance of Zoom as an e-learning platform that substantially and positively correlates with self-efficacy with the technology in use. Furthermore, Pal \& Patra (2021) examined the perceptions of 232 students who have taken part in a full-semester video-based online learning course during the pandemic. Their results showed that video-based learning positively fits into the student's perception and their actual use of the system.

Perceived learning success greatly depends on how learners perceive the learning process effectively. When learners have positive attitudes towards their learning process, they might promote a higher level of self-efficacy and, in turn, achieve higher learning outcomes (Gupta \& Bostrom, 2013; Hattie \& Yates, 2014; Janson 
et al., 2017). Moreover, Jan (2015) indicated that students' academic self-efficacy and computer self-efficacy in online education programs positively influence student academic motivation and satisfaction. Students' satisfaction with e-learning is linked with students' perceived learning from the online platform.

Landrum (2020) highlighted that the technology used must be clearly introduced to students to ease the online learning process and consequently enhance students' ability to perform successfully. Therefore, research assessing learners' attitudes and acceptance of video conferencing tools in online learning are necessary, especially when the institutions and learners are not well prepared for the new class delivery mode during emergency online courses like those experienced during the Covid-19 pandemic.

\section{Methods}

\subsection{Overview and participants}

This study followed a cross-sectional survey research design that used Davis's (1986) TAM framework to measure levels of PeoU, PU, attitude, behavioral intention, and learning outcome. A cross-sectional research design involves looking at data at a specific point in time. The data here pertained to perceptions and behavior with videoconference tools used to support EFL course learning objectives (e.g., develop English speaking and writing skills). The specific time of interest for this survey study was the second semester of fully online courses due to Covid-19. By the second semester, students were considered to have sufficient experience with the videoconference technology under investigation.

The participants in this study were a combination of freshmen and sophomore students attending conversational English courses in South Korea $(n=321 ; M=129$, $\mathrm{F}=192$ ), and ranged from a variety of majors including economics, logistics, nursing, nutrition, social welfare, chemistry, history, Korean, Chinese, and interior design. Criteria for inclusion into the study entailed students attending conversational English courses using the video conference platform Zoom taught by native English-speaking instructors. To accomplish communication goals with Zoom, the conversational English instructor first provided talking points for students to discuss with a partner or in small discussion groups and then separated students into their own sub-conference rooms (i.e., break-out rooms).

\subsection{The instrument}

The first part of the two-part questionnaire contained a nominal scale to collect basic information pertaining to demographic information such as gender, self-reported L2 proficiency, and academic major. This was followed by the second section that included the three TAM scales of interest, PEoU, PU, and behavioral intentions, which originated from Davis (1989) survey. The fourth variable, attitude, was developed in-house and pertained specifically to the learning activities performed through 
Zoom (e.g., partner and group speaking activities). For the actual use of video conference tools, five modified items from Bong \& Skaalvik's (2003) academic selfefficacy for learning scale were used. An original item states, "I can tell what is important in my class," while a modified item states, "I can tell what is important in my video conference class." These five items were chosen because they explicitly referred to learning that emanates from the actual use of the video conference platform. Table 1 lists each scale with its corresponding items. Participants were asked to respond using a 5-point interval scale for the five variables of interest, with one denoting strong disagreement and five as strong agreement with the statements.

\subsection{Data analysis}

Initially, the Statistical Package for Social Science (SPSS; Version 26.0) was used to calculate mean score and Pearson correlation analysis on the variables of interest. Next, Analysis of Moment Structure (AMOS; Version 21.0) was used for structural equation modeling. After data cleaning and an initial view of the data, the next step entailed a confirmatory factor analysis (CFA) with AMOS to develop the measurement model. After this, structural equation modeling was used to measure the causal relationships within the proposed structural model.

\subsection{Data cleaning}

Data cleaning initially entailed outlier analysis to check for irregularities within the data. Using linear regression, Mahalanobis and Cook's distance were used to check for outliers in which 11 existed and were consequently removed. Overall, fairly normal distributions were observed concerning indicators for the latent factors. Kurtosis and skewness values were in the acceptable range, between -1.0 and +1.0 , providing further support for normal univariate distribution (George \& Mallery, 2010). The study next looked at Variable Inflation Factors (VIF) to test for multicollinearity. In no case was a VIF greater than 3 observed, far below the upper threshold of 10 . Regarding the Kaiser-Meyer-Olkin measure (KMO) of sampling adequacy, a value of 0.901 was observed which was above the recommended value of 0.60 . Regarding Bartlett's Test of Sphericity, the value was significant $\left(\chi^{2}(55)=3498.50, p<0.001\right)$. Lastly, commonalities were above the recommended value of 0.50 (Kline, 2015). When complete, it was determined that the data were sufficient to proceed with structural equation modeling.

\section{Results and discussion}

\subsection{Results}

To measure linearity between the observed variables, bivariate Pearson correlation was calculated. All the observed variables of interest were significant in the medium to high levels, with $r$ values ranging from 0.292 to 0.643 (Cohen, 
Table 1 Survey scales and items

\section{Self-efficacy with learning expectations using Zoom}

1

2

3

4

5

\section{Perceived ease of use of video conference tools in class}

6

7

8

I am confident that I am learning in the English video conference class

I will do well in my English video conference class

I can tell what is essential in my English video conference class

I can easily understand what I am learning in my English video conference class

I can understand well even if the teacher presents complex materials in our English video conference class

Video conference learning tools are easy to use

Video conference learning tools are easy to learn

Interactions with video conferencing tools are clear and understandable

\section{Perceived usefulness with video conference tools in class}

9

10

12

Attitude with video conference tools in class

13

14

15

16

17

I think video conference learning tools improve learning efficiency

I think video conference learning tools improve my academic performance

I think video conference learning tools improve my efficiency in-class activities

I think video conference learning tools are useful

I enjoy taking video conference classes this semester

I enjoy attending my video conference class

I enjoy doing partner activities in our video conference class

I enjoy doing small group activities in our video conference course

I think it's a good idea to do partner activities in our video conference class

\section{Behavioral intention to use video conference learning tools in class}

18

19
I will use video conference tools frequently in the future

I want to use video conference learning tools frequently for class activities

1988). In addition to Pearson correlation, Table 2 displays mean score values for variables that ranged from 2.83 to 3.23 and standard deviations ranging from 0.70 to 0.83 . PEoU produced the highest mean and standard deviation, indicating moderate levels of variation in how students regarded comfort with using Zoom. Regarding gender, females reported a having a slightly better attitude towards Zoom activities, however, no other gender differences were noticed. L2 
Table 2 Mean scores and correlation

\begin{tabular}{|c|c|c|c|c|c|c|c|c|}
\hline & & 1 & 2 & 3 & 4 & 5 & 6 & 7 \\
\hline \multicolumn{9}{|c|}{ Gender } \\
\hline & L2 Proficiency & -0.045 & & & & & & \\
\hline 1 & Actual Use & 0.015 & $0.499^{* *}$ & & & & & \\
\hline 2 & Attitude & $0.130^{*}$ & 0.033 & $0.469^{* *}$ & & & & \\
\hline 3 & PEoU & -0.005 & $0.252^{* *}$ & $0.503^{* *}$ & $0.305^{* *}$ & & & \\
\hline 4 & PU & 0.052 & $0.181^{* *}$ & $0.413^{* *}$ & $0.348^{* *}$ & $0.600^{* *}$ & & \\
\hline \multirow[t]{6}{*}{5} & Behav. Intent & 0.107 & 0.069 & $0.321^{* *}$ & $0.292^{* *}$ & $0.501^{* *}$ & $0.643^{* *}$ & \\
\hline & M & 1.59 & 4.33 & 2.96 & 2.89 & 3.23 & 2.94 & 3.10 \\
\hline & SD & 0.49 & 1.73 & 0.78 & 0.70 & 0.83 & 0.75 & 0.70 \\
\hline & Kurt & -0.577 & -1.85 & -0.13 & -0.061 & -0.130 & 0.220 & 0.022 \\
\hline & Skew & 0.150 & -0.402 & -0.149 & 0.066 & -0.235 & 0.083 & 0.280 \\
\hline & Cron. alpha & N/A & N/A & 0.876 & 0.767 & 0.867 & 0.915 & 0.804 \\
\hline
\end{tabular}

** $=0.01$; LO, Learning Outcome; PEoU, Perceived ease of use; PU, Perceived usefulness; Behav. Intent., Behavioral intention; Gender $(\mathrm{M}=1, \mathrm{~F}=2)$; L2 Proficiency $(1=$ Low, $10=$ High $)$.

proficiency strongly correlated with actual use, and to a lesser extent, PEoU and PU.

\subsection{Validity checks}

The next step entailed checking convergent and discriminant validity to ensure the unidimensionality of the five-construct model. Cronbach alphas ranged from 0.77 to 0.92 , indicating adequate internal reliability (see Table 2), above the recommended 0.70 limit (Nunnally, 1994). Next, composite reliability scores were above the recommended 0.60 values. The average variance extracted was above the 0.50 value (Hair et al., 2006) except for attitude, which was 0.424. AVE's above 0.40 is considered adequate when Composite Reliability (CR) values are above 0.60 (Fornell \& Larker, 1981), which attitude safely was. The study proceeded to test the proposed model upon confirming validity (Table 3).

Table 3 Construct reliability, convergent validity, and discriminant validity

\begin{tabular}{|c|c|c|c|c|c|c|c|c|c|c|}
\hline & & $\mathrm{CR}$ & AVE & MSV & $\operatorname{MaxR}(\mathrm{H})$ & 1 & 2 & 3 & 4 & 5 \\
\hline 1 & Actual Use & 0.878 & 0.593 & 0.327 & 0.889 & 0.770 & & & & \\
\hline 2 & PEoU & 0.869 & 0.688 & 0.437 & 0.873 & 0.572 & 0.830 & & & \\
\hline 3 & Attitude & 0.781 & 0.424 & 0.279 & 0.816 & 0.528 & 0.373 & 0.651 & & \\
\hline 4 & Behav. Intent & 0.768 & 0.623 & 0.570 & 0.770 & 0.390 & 0.619 & 0.351 & 0.789 & \\
\hline 5 & PU & 0.917 & 0.735 & 0.570 & 0.922 & 0.445 & 0.661 & 0.369 & 0.755 & 0.858 \\
\hline
\end{tabular}




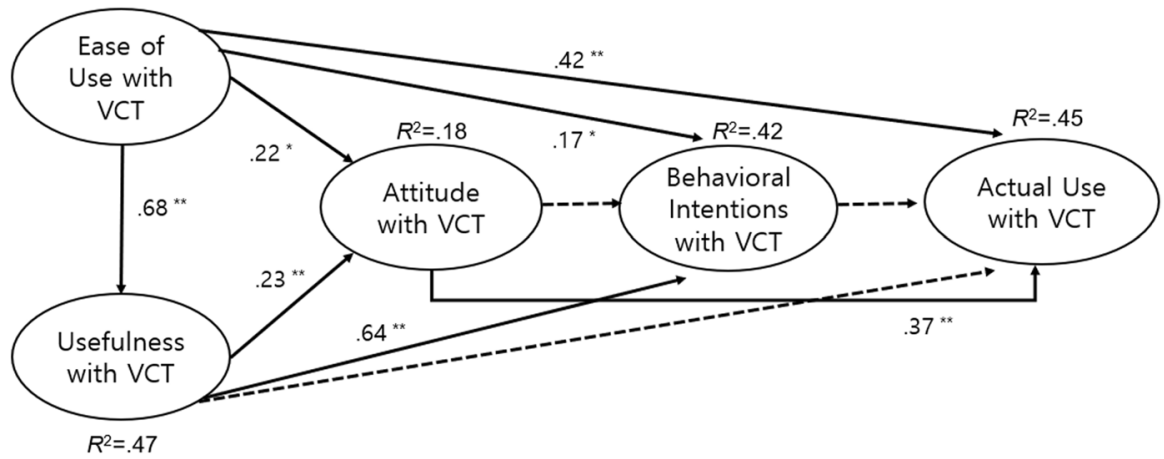

Fig. 2 The final model with regression weights and path coefficients

Table 4 Confirmed hypotheses with path coefficient regression weights

\begin{tabular}{llllllll}
\hline & Path & Hypothesis & $B$ & S.E & $\beta$ & $p$ & $R^{2}$ \\
\hline H1 & PEoU PU & +/ Confirmed & 0.619 & 0.058 & 0.676 & $0.000^{* *}$ & 0.47 \\
H2 & PEoU ATT & +/ Confirmed & 0.232 & 0.099 & 0.216 & $0.019^{*}$ & 0.18 \\
H3 & PU ATT & +/ Confirmed & 0.275 & 0.107 & 0.233 & $0.010^{* *}$ & \\
H4 & PEoU BI & +/ Confirmed & 0.143 & 0.065 & 0.169 & $0.031^{* *}$ & 0.42 \\
H5 & PU BI & +/ Confirmed & 0.583 & 0.077 & 0.638 & $0.000^{* *}$ & \\
H6 & ATT BI & Null & 0.035 & 0.046 & 0.048 & 0.446 & \\
H7 & PU AU & Null & 0.041 & 0.099 & 0.050 & 0.677 & 0.45 \\
H8 & PEoU AU & +/ Confirmed & 0.366 & 0.074 & 0.413 & $0.000^{* *}$ & \\
H9 & BI AU & Null & -0.030 & 0.110 & -0.030 & 0.787 & \\
H10 & ATT AU & +/ Confirmed & 0.293 & 0.053 & 0.369 & $0.000^{* *}$ & \\
\hline
\end{tabular}

$\mathrm{p}^{* *}=0.01 ; \mathrm{p}^{*}=0.05 ; \mathrm{AU}$, Actual use; PEoU, Perceived ease of use; PU, Perceived usefulness; ATT, Attitude; BI, Behavioral intention.

\subsection{Structural model}

Confirmatory factor analysis with AMOS was used to estimate the model's parameter. Goodness-of-fit was reached using a series of recommended indices, including the Root Mean Square Error of Approximations (RMSEA), Comparative Fit Index (CFI), and Normal Fit Index (NFI) (Hair et al., 2006; Kline, 2015). The structural equation model, upon adjusting according to the modification indices, produced a good fit $\left(\chi^{2} / \mathrm{df}=2.158, p<0.001 ; \mathrm{TLI}=0.942 ; \mathrm{CFI}=0.952 ; \mathrm{NFI}=0.925\right.$; RMSEA $=0.059$; PCLOSE $=0.060$ ). Figure 2 displays the final model with regression weights and path coefficients. The significant paths are shown as solid lines and insignificant paths as dotted ones (Table 4).

For the statistically significant findings, varying effect sizes were found amid the path coefficients. The highest path coefficient was from PEoU to PU, producing a total regression weight $\left(R^{2}\right)$ of $0.47(\mathrm{p}<0.001)$. To a lesser degree, in the low 
effect size range (Cohen, 1988), both PEoU and PU had positive path coefficients to reported levels of attitude using video conference tools, producing a total regression weight $\left(R^{2}\right)$ of $0.18(\mathrm{p}<0.001)$. PU was the strongest predictor for behavioral intentions, indicating that utility in the video conferencing system is an essential antecedent for future use. While PEoU revealed a statistically significant path to behavioral intentions to use video conferencing tools in the educational context, the path was in the low effect size range (Cohen, 1988). Together, PU and PEoU produced a total regression weight $\left(R^{2}\right)$ of $0.42(\mathrm{p}<0.001)$ on behavioral intention to use Zoom for English conversational purposes. Regarding actual use, only PEoU and attitude produced significant path coefficients, accounting for an overall total regression weight $\left(R^{2}\right)$ of $0.45(\mathrm{p}<0.001)$.

Results from post hoc analysis using a 5000-sample bootstrap revealed two instances of mediation. For every one-point increase in PEoU (on the five-point Likert scale), there was an indirect effect through PU that accounted for a 0.337-point increase in reported levels of behavioral intention to use video conference tools in the future, equating to a standardized regression weight of $0.437(p<0.001)$. Following a similar path through PU, for every one-point increase in PEoU, there was a statistically significant indirect effect through PU that accounted for a 0.163 -point increase in reported attitude with using video conference tools for conversational English classes, equating to a standardized regression weight of $0.147(p=0.023)$. The next chapter explains these findings through the lens of past literature.

\subsection{Discussion}

In the current research, the Zoom video conference platform was evaluated using a modified version of the TAM. The study's model helps explain the adoption of video conference tools during the Covid-19 pandemic. For the modified TAM, actual use was substituted with perceived learning outcome as it pertains to direct participation with video conference tools. Several points of significance surfaced from our study. From the initial review of data, bivariate Pearson correlation analysis found that all variables shared statistically significant relationships with one another, which is a common emergence within TAM literature (Park, 2009). Once testing the structural model, a multivariate understanding of how these constructs related to one another was observed. For seven of the ten proposed hypotheses, paths were in the anticipated positive direction, adding credit to the reliable nature of the TAM's application with educational technology in general and video conference tools specifically.

\subsubsection{Hypotheses 1 to 3}

Hypotheses one was confirmed, indicating that perceived ease of use positively affects perceived usefulness with video conference tools, and this finding is directly in line with extant literature (Almaiah et al., 2020; Mohammadi, 2015; Sukendro et al., 2020). PEoU produced the highest path coefficient in the model with PU, echoing past studies in reference to LMS technology (Cheung \& Vogel, 2013) and in line with the growing literature pertaining specifically to video conference tools for 
e-learning purposes (Coman et al., 2020). Hypotheses two, perceived ease of use positively affected attitude using video conference tools, and three, perceived usefulness positively affects attitudes towards using video conference tools, were also confirmed, supporting similar findings from recent studies (Buabeng-Andoh et al., 2019; Muhaimin et al., 2019; Sukendro et al., 2020). These findings indicate that Zoom's ease of use and PU in conversational English courses contribute to improved attitudes towards communication tasks, including partner and group EFL speaking activities.

\subsubsection{Hypotheses 4 to 6}

Hypotheses four and five confirmed that perceived ease of use and perceived usefulness positively affect behavioral intentions to use video conference tools. PEoU positively affected intentions to use zoom but not at as high a level as PU, which is in line with similar TAM patterns recognized by Zhang et al. (2008) and Yang \& Wang (2019). Technology that is perceived as applicable helps students (Zaharias, 2009), contributing to future use with the Zoom video conference platform for classroom purposes. To a lesser degree than with PU, PEoU positively affected intentions to use video conference tools in the future, and this result ties well with previous studies (Nikou \& Economides, 2017; Sukendro et al., 2020; Teo et al., 2018).

Hypothesis six, attitude positively affects behavioral intentions with video conference tools, was rejected. A different result was obtained from previous studies wherein Saadé et al. (2007) indicated that PU has a significant favorable influence on university learners' attitude toward online environments as well as their behavioral intention to use such technology in the future. Therefore, our primary findings pertaining to attitude contradict prior research, showing that attitude was a key indicator in acceptance behavior (Alharbi \& Drew, 2014; Cheung \& Vogel, 2013). Reasoning for this may be attributed to the wording of the items in the in-house developed attitude scale. Students reported on their attitude towards conversational English activities delivered through Zoom, but not Zoom features specifically, which may have influenced the findings.

\subsubsection{Hypotheses 7 to 10}

Hypothesis seven, perceived usefulness positively affects reported learning outcomes with video conference tools, was rejected. This finding was in stark contrast to past TAM studies prior to Covid and outside the video conference context (Al-Gahtani, 2016; Chang et al., 2017; Lee et al., 2014; Tarhini et al., 2014). Students recognized that video conference tools had been used for e-learning purposes in general and even for EFL classes specifically. However, increased levels of perceived usefulness did not influence increased levels of perceived learning outcome with the Zoom conversational English classes under investigation here.

Next, the study revealed that hypothesis eight, perceived ease of use positively affects reported learning outcomes with video conference tools, was confirmed. When comparing our results to prior TAM studies (Gupta \& Bostrom, 2013; Hattie \& Yates, 2014; Janson et al., 2017), it must be pointed out that success in 
accomplishing learning goals often relies on how efficient learners perceive the learning program and their learning development. When learners have positive attitudes towards their learning development, they gain a higher level of self-efficacy and, consequently, achieve higher learning outcomes.

With the video conference technology referenced here, perceived usage, or how students reported their level of learning while participating in the video conference course, was used to define actual use in the tested TAM. PEoU positively influenced perceived levels of learning, indicating that self-efficacy with the technology regarding ease of use contributes to self-efficacy with learning expectations when using that technology. PEoU predicted learning outcomes (e.g., mastering conversational EFL activities), while PU did not. As less effort is exerted when using the e-learning tools, more time and energy can be dedicated to the learning activity, contributing to a higher likelihood of mastering the course objective. Contrarily, students who may or may not feel they are mastering the content may still judge the video conference tools as beneficial; however, this is independent of how well they perceive their performance when attending video conference courses.

Hypothesis nine, behavioral intention positively affects reported learning outcomes with video conference tools, was rejected. Behavioral intention to use video conference tools in the future did not predict actual use in the context of conversational English courses, which contrasts with extant TAM literature (Sukendro et al., 2020; Zhang et al., 2008). Finally, hypothesis ten, attitude positively affects reported learning outcomes with video conference tools, was confirmed. This is consistent with what has been found in previous research, which found that attitude positively affected the actual use of video conference tools for e-learning purposes to offset complications brought on by the Covid-19 pandemic (Pal \& Patra, 2021).

\subsubsection{Mediation results}

Through post hoc analysis, two instances of mediation were identified. Specifically, PU mediated the relationship between PEoU and behavioral intentions, repeating similar findings with video conference courses taught during the Covid-19 pandemic (Utami, 2021) as well as earlier TAM studies (Wu \& Chen, 2017). Further, PU mediated the relationship between PEoU and attitude, supporting prior mediation found with the TAM among a group of MOOC students and their choice to continue to participate in their massive online course (Wu \& Chen, 2017). If video conference tools provide critical functionality, students will have a better attitude to using them, and this perceived usefulness will equate to a better attitude and more engagement.

\subsubsection{Pedagogical implications}

The main practical contribution of the study is that it offers evidence from the students' perspective for the acceptance level of continuing use of video conferencing systems for teaching in the post-Covid-19 era. In addition to the added contributions to the TAM literature, evidence emerged arguing for training sessions to be organized by the administrators within universities outside the regular classroom sessions 
to familiarize students with the video-based learning systems and discuss possible solutions to reported challenges. Instructors should also be informed about the features, usefulness, and technical issues of the newly implemented video conferencing platform to extend their knowledge and confidence in using the system. For instance, the resolution of the delivered videos should be optimal to cater to the needs of all the students who might encounter Internet speeds and or data plan restrictions (Pal \& Patra, 2021). Preparation sessions should be delivered to all learners reassuring the availability of mentoring and technical support to enhance their self-confidence and, thereby, positively influencing learners' technology acceptance.

Moreover, a deeper examination of teachers' and students' attitudes on specific features of Zoom's break-out rooms, whiteboards, and screen sharing would be practical to further guide the transformation from traditional in-person instructions to online multimodalities. Technology orientation and continuous support are vital factors that lead to proficient skills and a positive attitude toward the learning system to be utilized promptly and effectively. To support the users more efficiently, universities should connect video conferencing features to the specific types of learning activities performed on the conferencing platform. System designers need such information to acknowledge learners' needs during the learning process and, thus, ensure that learners receive IT support when needed. Moreover, video conferencing platforms must enhance the system's usefulness and ease of use to maximize learners' acceptance. Educational stakeholders should also consider the acceptability of the used learning platform. Therefore, it is suggested that efforts should be directed toward knowing the reasons behind why a planned platform might not be entirely acceptable and preparing for improvement actions accordingly. Collecting feedback from the users of the video conferencing platform about the accessibility issues, problems, and recommendations for improvement is essential to optimize the effectiveness of e-learning.

The study concluded that the TAM affected university students' intention to use Zoom as a learning tool. As a result, there is the possibility of practical application in the development and management of Zoom in the university context. Stakeholders, including educators and policymakers, should work to develop ongoing training for educators to improve students' ability to use Zoom, improve their skills, and increase levels of acceptance toward e-learning platforms. E-learning course instructional design, motivation, communication, and support contribute to improved learning outcomes. As we enter a post-pandemic pedagogy, innovative plans and customized lesson designs within blended learning are desperately needed.

\section{Conclusion}

The main conclusion drawn is that PEoU with Zoom strongly affected PU, attitude, and perceived levels of learning when using the platform. Further, PU with Zoom predicted intentions to use Zoom in the future, directly and indirectly, on the relationship between PEoU and behavioral intentions; however, PU failed to influence perceived learning outcomes in the video conference class. Therefore, while PU 
predicted future use, it did not influence how well students reported their current performance in their video conference course.

\subsection{Limitations and future direction}

There are several limitations to this study that future research can address. Some of the shortcomings include but are not limited to the fact that the data is conducted during emergency remote online classes in response to the Covid-19 pandemic. The settings surrounding the transfer to, and continuation with, online instruction was not the preferred mode of educational delivery, yet allowed a unique opportunity to gauge learner perceptions, expectations, and acceptance of video conference instruction with Zoom. Next, this study did not investigate external variables such as subjective norm, perceived interaction, self-efficacy with video conference tools, or joyfulness in TAM-based models. Furthermore, future work can include user log data for the actual use of Zoom features. Another drawback of this study is the use of Zoom as the only reference platform for assessing the PU and PEoU of the online learning platforms. Comparative research should be undertaken to examine whether a difference exists between other platforms (e.g., Skype, WebEx, and Google Meet). Future research should focus on measuring two or more e-learning platforms to bring out the natural state of the art of the claimed findings.

Future research should further develop and confirm these initial findings by conducting the study in different settings and by using a triangulation of data collections (e.g., classroom observations, focus individual and group interviews, artifacts). Further, research-based on self-report or system log files of actual use of the Zoom platform should be carried out to evaluate the validity of the results with the original TAM variables. Additionally, this study targeted only students; it would be wise to implement research with instructors and professors in the university. Moreover, the geographical location of the participants (i.e., one specific country) is a point of delimitation considering the usage behavior, and thus, the perception of usability could change with culture. Therefore, future studies could replicate results in a larger and international context that includes digital equality and gender inclusion as moderators for anticipating the actual usage of video-based systems to generalize the current findings.

Video conference software has permanently made its mark as the remedy for emergency online classes. Due their success, students, instructors, and administrators will likely adopt video conference tools more frequently and for reasons beyond social distancing measures. To this end, there continues to be a clear and present need to understand how video conference features with software like Zoom are incorporated as novel and effective learning environments that help meet academic objectives.

Acknowledgment The researchers thank Prince Sultan University for funding this research project under grant [Education Research Lab- [ERL-CHS-2022/1]. In addition, this paper was supported by Konkuk University. Further, this paper was supported by Imam Mohammad Ibn Saud Islamic University (IMSIU). 
Author contribution Dr. Daniel Bailey (data collection and analysis).

Dr. Norah Almusharraf (theoretical framework).

Dr. Asma Almusharraf (report and narratives).

\section{Declarations}

Conflict of interests statement Conflict of interests-None

\section{References}

Abdullah, F., \& Ward, R. (2016). Developing a general extended technology acceptance model for e-learning (GETAMEL) by analyzing commonly used external factors. Computers in Human Behavior, 56, 238-256. https://doi.org/10.1016/j.chb.2015.11.036

Alfadda, H. A., \& Mahdi, H. S. (2021). Measuring students' use of Zoom application in language course based on the Technology Acceptance Model (TAM). Journal of Psycholinguistic Research, 50, 1-18. https://doi.org/10.1007/s10936-020-09752-1

Alharbi, S., \& Drew, S. (2014). Using the technology acceptance model in understanding academics' behavioral intention to use learning management systems. International Journal of Advanced Computer Science and Applications, 5(1), 143-155. https://doi.org/10.14569/IJACSA.2014. 050120

Almaiah, M. A., Al-Khasawneh, A., \& Althunibat, A. (2020). Exploring the critical challenges and factors influencing the E-learning system usage during COVID-19 pandemic. Education and Information Technologies, 25, 5261-5280. https://doi.org/10.1007/s10639-020-10219-y

Al-Gahtani, S. S. (2016). Empirical investigation of e-learning acceptance and assimilation: A structural equation model. Applied Computing and Informatics, 12(1), 27-50. https://doi.org/10.1016/j.aci. 2014.09.001

Al-Samarraie, H. (2019). A scoping review of videoconferencing systems in higher education: Learning paradigms, opportunities, and challenges. International Review of Research in Open and Distributed Learning, 20(3). https://doi.org/10.19173/irrodl.v20i4.4037

Bong, M., \& Skaalvik, E. M. (2003). Academic self-concept and self-efficacy: How different are they really? Educational Psychology Review, 15(1), 1-40. https://doi.org/10.1023/A:1021302408382

Buabeng-Andoh, C., Yaokumah, W., \& Tarhini, A. (2019). Investigating students' intentions to use ICT: A comparison of theoretical models. Education and Information Technologies, 24, 643-660. https:// doi.org/10.1007/s10639-018-9796-1

Bui, T. H., Luong, D. H., Nguyen, X. A., Nguyen, H. L., \& Ngo, T. T. (2020). Impact of female students' perceptions on behavioral intention to use video conferencing tools in COVID-19: Data of Vietnam. Data in Brief, 32, 106-142. https://doi.org/10.1016/j.dib.2020.106142

Chang, C.-T., Hajiyev, J., \& Su, C.-R. (2017). Examining the students' behavioral intention to use e-learning in Azerbaijan? The general extended technology acceptance model for e-learning approach. Computers \& Education, 111, 128-143. https://doi.org/10.1016/j.compedu.2017.04.010

Cheung, R., \& Vogel, D. (2013). Predicting user acceptance of collaborative technologies: An extension of the technology acceptance model for e-learning. Computers \& Education, 63, 160-175. https:// doi.org/10.1016/j.compedu.2012.12.003

Chuttur, M. Y. (2009). Overview of the technology acceptance model: Origins, developments and future directions. Sprouts: Working Papers on Information Systems, 9(37), 1-21. http://sprouts.aisnet. org/9-37

Cohen, J. (1988). Statistical power analysis for the behavioral sciences (2nd ed.). Erlbaum.

Coman, C., Tiru, L. G., Mesesan-Schmitz, L., Stanciu, C., \& Bularca, M. C. (2020). Online teaching and learning in higher education during the Coronavirus Pandemic: Students' perspective. Sustainability, 12(24), 1-24. https://doi.org/10.3390/su122410367

Crosthwaite, P. R., Bailey, D. R., \& Meeker, A. (1986). Assessing in-class participation for EFL: Considerations of effectiveness and fairness for different learning styles (2015). Language Testing in Asia, 5(9), 1-18. https://doi.org/10.1186/s40468-015-0017-1 
Crosthwaite, P. R., Bailey, D. R., \& Meeker, A. (2015). Assessing in-class participation for EFL: considerations of effectiveness and fairness for different learning styles. Language Testing in Asia, 5(1), 1-19. https://doi.org/10.1186/s40468-015-0017-1

Davis, F. D. (1986). A technology acceptance model for empirically testing new end-user information systems: theory and results, [doctoral dissertation, MIT Sloan School of Management]. Cambridge, MA. Retrieved from http://dspace.mit.edu/handle/1721.1/15192.

Davis, F. D. (1989). Perceived usefulness, perceived ease of use, and user acceptance of information technology. MIS Quarterly, 13(3), 319-340. https://doi.org/10.2307/249008

Farr, F., \& Murray, L. (Eds.). (2016). The Routledge handbook of language learning and technology. Routledge.

Fishbein, M., \& Ajzen, I. (1975). Belief, attitude, intention and behavior: An introduction to theory and research. Addison-Wesley.

Fornell, C., \& Larcker, D. F. (1981). Evaluating structural equation models with unobservable variables and measurement error. Journal of Marketing Research, 18(1), 39-50. https://doi.org/10.1177/ 002224378101800104

George, D., \& Mallery, M. (2010). SPSS for Windows step by step: A simple study guide and reference, 17.0 update $\left(10^{\text {th }}\right.$ ed.). Allyn \& Bacon.

Granic, A., \& Marangunic, N. (2019). Technology acceptance model in educational context: A systematic literature review. IEEE Access, 28(2), 273-315. https://doi.org/10.1111/bjet.12864

Gupta, S., \& Bostrom, R. (2013). An investigation of the appropriation of technology-mediated training methods incorporating enactive and collaborative learning. Information Systems Research, 24(2), 454-469.

Hair, J. F., Black, W. C., Babin, B. J., \& Anderson, R. E (2006). Multivariate data analysis (6th ed.). Pearson College Division.

Hattie, J., \& Yates, G. C. R. (2014). Visible learning and the science of how we learn. Routledge.

Ho, N. T. T., Sivapalan, S., Pham, H. H., Nguyen, L. T. M., Van Pham, A. T., \& Dinh, H. V. (2020). Students' adoption of e-learning in emergency situations: The case of a Vietnamese university during COVID-19. Interactive Technology and Smart Education, 17(4), 1-24. https://doi.org/10.1108/ ITSE-08-2020-0164

Jan, S. K. (2015). The relationships between academic self-efficacy, computer self-efficacy, prior experience, and satisfaction with online learning. American Journal of Distance Education, 29(1), 30-40. https://doi.org/10.1080/08923647.2015.994366

Janson, A., Söllner, M., \& Leimeister, J. M. (2017). Individual appropriation of learning management systems-antecedents and consequences. AIS Transactions on Human-Computer Interaction, 9(3), 173-201. 10 .17705/1 thci.00094

Kline, R. B. (2015). Principles and practice of structural equation modeling. Guilford Publications.

Landrum, B. (2020). Examining students' confidence to learn online, self-regulation skills and perceptions of satisfaction and usefulness of online classes. Online Learning, 24(3), 128-146. https://doi. org/10.24059/olj.v24i3.2066

Lee, Y. H., Hsiao, C., \& Purnomo, S. H. (2014). An empirical examination of individual and system characteristics on enhancing e-learning acceptance. Australasian Journal of Educational Technology, 30(5), 561-579. https://doi.org/10.14742/ajet.381

Mader, C., \& Ming, K. (2015). Videoconferencing: A new opportunity to facilitate learning: The clearing house: A Journal of Educational Strategies. Issues and Ideas, 88(4), 109-116. https://doi.org/10. 1080/00098655.2015.1043974

Mailizar, M., Burg, D., \& Maulina, S. (2021). Examining university students' behavioral intention to use e-learning during the COVID-19 pandemic: An extended TAM model. Education and Information Technologies, 1-21. https://doi.org/10.1007/s10639-021-10557-5

Mishra, L., Gupta, T., \& Shree, A. (2020). Online teaching-learning in higher education during lockdown period of COVID-19 pandemic. International Journal of Educational Research, 1, 100012. https:// doi.org/10.1016/j.ijedro.2020.100012

Mohammadi, H. (2015). Investigating users' perspectives on e-learning: An integration of TAM and IS success model. Computers in Human Behavior, 45, 359-374. https://doi.org/10.1016/j.chb.2014.07. 044

Muhaimin, M., Habibi, A., Mukminin, A., Pratama, R., Asrial, A., \& Harja, H. (2019). Predicting factors affecting intention to use Web 20 in learning: Evidence from science education. Journal of Baltic Science Education, 18(4), 595-606. https://doi.org/10.33225/jbse/19.18.595 
Nikou, S. A., \& Economides, A. A. (2017). Mobile-based assessment: Investigating the factors that influence behavioral intention to use. Computers \& Education, 109, 56-73. https://doi.org/10.1016/j. compedu.2017.02.005

Nunnally, J. C. (1994). Psychometric theory 3E. Tata McGraw-hill education.

Pajo, K., \& Wallace, C. (2001). Barriers to the uptake of web-based technology by university teachers. The Journal of Distance Education, 16(1), 70-84.

Pal, D., \& Patra, S. (2021). University students' perception of video-based learning in times of COVID19: A TAM/TTF perspective. International Journal of Human-Computer Interaction, 37(10), 903921.https://doi.org/10.1080/10447318.2020.1848164

Pal, D., \& Vanijja, V. (2020). Perceived usability evaluation of Microsoft Teams as an online learning platform during COVID-19 using system usability scale and technology acceptance model in India. Children and Youth Services Review, 119, 105535. https://doi.org/10.1016/j.childyouth.2020. 105535

Park, S. Y. (2009). An analysis of the technology acceptance model in understanding university students' behavioral intention to use e-learning. Educational Technology \& Society, 12(3), 150-162. Retrieved July 25, 2021, from http://www.jstor.org/stable/jeductechsoci.12.3.150

Park, S. Y., Nam, M.-W., \& Cha, S.-B. (2012). University students' behavioral intention to use mobile learning: Evaluating the technology acceptance model. British Journal of Educational Technology, 43(4), 592-605. https://doi.org/10.1111/j.1467-8535.2011.01229.x

Pituch, K. A., \& Lee, Y.-K. (2006). The influence of system characteristics on e-learning use. Computers \& Education, 47(2), 222-244. https://doi.org/10.1016/j.compedu.2004.10.007

Revythi, A., \& Tselios, N. (2019). Extension of technology acceptance model by using system usability scale to assess behavioral intention to use e-learning. Education and Information Technologies, 24(4), 2341-2355.

Saadé, R. G., Nebebe, F., \& Tan, W. (2007). Viability of the technology acceptance model in multimedia learning environments: Comparative study. Interdisciplinary Journal of Knowledge and Learning Objects, 3(1), 175-184. https://www.learntechlib.org/p/44804/

Sukendro, S., Habibi, A., Khaeruddin, K., Indrayana, B., Syahruddin, S., Makadada, F. A., \& Hakim, H. (2020). Using an extended Technology Acceptance Model to understand students' use of e-learning during Covid-19: Indonesian sport science education context. Heliyon, 6(11), online journal. https:// doi.org/10.1016/j.heliyon.2020.e05410.

Taat, M. S., \& Francis, A. (2020). Factors influencing the students acceptance of E-learning at teacher education institute: An exploratory study in Malaysia. International Journal of Higher Education, 9(1), 133-141. https://doi.org/10.5430/ijhe.v9n1p133

Tarhini, A., Hone, K., \& Liu, X. (2014). Measuring the moderating effect of gender and age on e-learning acceptance in England: A structural equation modeling approach for an extended technology acceptance model. Educational Computing Research, 51(2), 163-184. https://doi.org/10.2190/EC.51.2.b

Teo, T., Sang, G., \& Mei, B. (2018). Investigating pre-service teachers' acceptance of Web 20 technologies in their future teaching: a Chinese perspective. Interactive Learning Environments, 27(4), 530546. https://doi.org/10.1080/10494820.2018.1489290

Utami, T. L. W. (2021). Technology adoption on online learning during Covid-19 pandemic: implementation of technology acceptance model (TAM). Diponegoro International Journal of Business, 4(1), 8-19. https://doi.org/10.14710/dijb.4.1.2021.8-19

Venkatesh, V., \& Bala, H. (2008). Technology Acceptance Model 3 and a research agenda on interventions. Decision Sciences, 39(2), 273-315. https://doi.org/10.1111/j.1540-5915.2008.00192.x

Virtič, M. P., Dolenc, K., \& Šorgo, A. (2021). Changes in online distance learning behaviour of university students during the coronavirus disease 2019 outbreak, and development of the model of forced distance online learning preferences. European Journal of Educational Research, 10(1), 393-411. https://doi.org/10.12973/eu-jer.10.1.393

Vladova, G., Ullrich, A., Bender, B., \& Gronau, N. (2021). Students' Acceptance of technology-mediated teaching-how it was influenced during the COVID-19 pandemic in 2020: A Study from Germany. Frontiers in Psychology, 12(1), 1-15. https://doi.org/10.3389/fpsyg.2021.636086

Wu, B., \& Chen, X. (2017). Continuance intention to use MOOCs: Integrating the technology acceptance model (TAM) and task technology fit (TTF) model. Computers in Human Behavior, 67, 221-232. https://doi.org/10.1016/j.chb.2016.10.028

Yang, Y., \& Wang, X. (2019). Modeling the intention to use machine translation for student translators: An extension of Technology Acceptance Model. Computers \& Education, 133, 116-126. https://doi. org/10.1016/j.compedu.2019.01.015 
Zaharias, P. (2009). Usability in the context of e-learning: A framework augmenting 'traditional usability constructs with instructional design and motivation to learn. International Journal of Technology and Human Interaction (IJTHI), 5(4), 37-59. https://doi.org/10.4018/jthi.2009062503

Zhang, S., Zhao, J., \& Tan, W. (2008). Extending TAM for online learning systems: An intrinsic motivation perspective. Tsinghua Science \& Technology, 13(3), 312-317.

Publisher's note Springer Nature remains neutral with regard to jurisdictional claims in published maps and institutional affiliations.

\section{Authors and Affiliations}

\section{Daniel R. Bailey ${ }^{1} \cdot$ Norah Almusharraf $^{2} \cdot$ Asma Almusharraf $^{3}$}

Daniel R. Bailey

dbailey056@kku.ac.kr

Norah Almusharraf

nmusharraf@psu.edu.sa

1 English Language and Literature Department, Konkuk University's Glocal Campus, Chungju, South Korea

2 Linguistics and Translation, Prince Sultan University, Riyadh, Kingdom of Saudi Arabia

3 College of Languages and Translation at Imam Mohammad Ibn Saud Islamic University (IMSIU), Riyadh, Kingdom of Saudi Arabia 